\title{
THE EFFECT OF ILLUMINATION, NOISE AND TEXT BACKGROUND COLOUR COMBINATION ON READABILITY OF WEBPAGES
}

\author{
Syed Noorul Hasan', W.M.Shewakh² \\ 1 Industrial Engineering Department, Faculty of Engineering, Jazan University, KSA \\ 2 Production Technology Department-IE College - Beni-Suef University, Egypt \\ waleedshewakh@hotmail.com
}

\begin{abstract}
Internet and the World Wide Web have had a great development and have become an inseparable part of human life. Several studies have reported investigations regarding the use of visual displays. However, it is generally recognized that there is a need to find the levels of environmental factors and text-background colour combination which may create comfort/discomfort to the users. Therefore, this study investigates the effects of ambient illumination, equivalent noise and text-background colour combination on reading performance of two groups of subjects between age 20 and 31 years; one group having exposure to Internet of less than 2 hours/ day and the second group having more than 2 hours of net exposure per day. Results showed that reading time performance was not significantly affected by ambient illumination (150 lx $-525 \mathrm{~lx}$ ) for both groups of users. On the contrary, reading time for both groups of users was significantly affected by both equivalent noise and text - background colour combination.
\end{abstract}

Keywords: Readability, Equivalent Noise Pressure, Illumination, Text Background Colour Combination.

\section{INTRODUCTION}

Internet has become an essential and inseparable part of human life. Because of the versatility of the internet, enormous growth has been observed in user population as we increasingly rely on computers for our every day jobs such as sending emails, banking and so on. The internet user population belongs to every age group representing almost every walk of life. People "depending on their need" use internet for different durations. The observation of Chevalier and Bonnardel [1] appeared to be of great significance in the light of the findings that persons of different age groups do not perform in the same way. Apart from various factors intrinsic to computers, users are exposed to environmental factors like noise and illumination. Proper ambient illumination is a must for better performance as poorly lighted work environment could result in impaired vision [2]. Eye problems get aggravated due to inappropriate lighting [3]. The other factor noise has also been shown to affect performance [4]. Noise has been observed to be an interfering factor and was responsible for change in heart rate, blood pressure, skin temperature etc. [5]. An improper working 
environment may lead to impaired productivity, while a harmful environment may cause users to experience a lot of stress. A number of design issues appear to remain unresolved in developing a proper web page. For example, the studies conducted by Schaik and Ling [6,7] show that design guidelines are important for web designers to produce more usable web pages if they are based on experimental research and not on personal experiences and observations [8,9], raising doubts as to their validity. These issues throw a challenge to human factors engineers to present a more efficient system, needed for today's working environment, where apart from visual display unit (VDU) related functions, environmental stressors are also to be given due consideration. Visual attention on the screen is necessary for better performance and prevention of human error. Since it is dependent on a number of environmental factors, distraction from the task could take place, leading to mental load and fatigue. Thus they should be designed keeping in mind both regular and nonspecialist users. Consideration of environmental stressors becomes all the more important in the light of the fact that a large number of user populations are accessing information using internet from almost everywhere.

Studies conducted on visual display units have shown that proper illumination level was needed to improve task performance in human computer interactions. A few studies have recommended an ambient lighting in the range of 200 to $450 \mathrm{~lx}$ for CRT based work stations for better performance (ANSI/HFS 100-1988, 1988; [10,11]. In another study $\mathrm{Xu}$ and $\mathrm{Zhu}$ (1990) found that increase in ambient illumination deteriorates the performance in work. Kubo et al. [12] also stated that ambient illumination affects character identification performance. This character performance identification is the main part of reading task. Hence, it is important to investigate the effect of illumination in reading task performance.

Another factor that has been reported as responsible for change in the WebPages reading task is colour combinations. Studies in the literature have reported the effect of text / background colours on task performance $[13,14]$. Ingraham and Bradburn [15] reported that the colour was one of the basic factors to be considered for designing a highly readable web page. The best colour combination that maximizes readability of on-screen displays is an important issue. This presents obviously a very broad spectrum of variables. The colour combination of the character/background of source document is an important factor in VDU text entry task. Text background colour of display constitute one of the variables that has been found to be having significant effect on performance of user population specially for WebPages using desktop and laptop type computing system. The effect of combination of text and background colour on visual search performance and subjective preference shows that higher contrast between text and background colour led to faster searching and were rated more favourably $[6,7]$. Investigating the effects of screen layout on the usability of a large number of colour combination options for customized product, It was found the display of colour samples modular sections to be the optimal method of colour selection. Search time is reduced since users view various product colour combinations directly with or without the aid of colour names; and there is greater user satisfaction. The research on designing optimal VDU parameters epitomize 
blue/white colour combination for reading WebPages [16].

"Noise" a well-known environmental stressor, might be responsible for the increase in irritation, blood pressure, and negative psychological mood [17]. Office workers reported that they will be able to concentrate more and perform reading task better in the absence of noise in work environment [16].

However, no study is found to show the combined/interaction effects of illumination level, text background-colour combination and noise level on reading task performance in terms of reading time (seconds). Therefore in the present investigation it is decided to test the following Null Hypothesis on the two participating groups; one group (called Group 1) having subjects with Internet exposure duration of less than two hours per day; and the second group (called Group 2) having subjects with internet exposure duration of greater than two hours per day:

The Null Hypothesis is that:

There is no significant effect of illumination level, text-background colour combination and equivalent noise pressure level on reading time for web based pseudo-task for the two groups of participants

\section{METHODOLOGY}

\subsection{SUBJECTS}

A sample of 350 Saudi male adult students between age 21 and 30 years and belonging to engineering and science faculty with the attribute that they used the Internet for either 2 hours or less; or net exposure was for 2 hours or more, were contacted and requested to participate in the experiment. However, only 254 students responded to voluntarily participate in the experimental investigation, out of which a pool of 198 was consciously selected for the present work based on the fact that they were active, healthy and had normal or corrected to normal vision with no color blindness. The selected subjects were then divided equally in two groups: Group 1: Internet usage duration less than 2 hours/day; Group 2: Internet usage duration more than 2 hours/day. Each subject's participation was restricted to one experiment only. Table 1 gives the characteristics of the participating subjects.

TABLE 1: CHARACTERISTICS OF THE SUBJECTS PARTICIPATING IN THE STUDY

\begin{tabular}{|c|c|c|c|c|}
\hline \multirow{2}{*}{$\begin{array}{c}\text { Age group } \\
\text { (Year) }\end{array}$} & \multicolumn{3}{|c|}{ Internet use duration/day } \\
\cline { 2 - 5 } & $\begin{array}{c}\text { Mean age } \\
\text { +SD }\end{array}$ & Vision & $\begin{array}{c}\text { Mean age } \\
\text { +SD }\end{array}$ & Vision \\
\cline { 2 - 5 } & $24.6+2.3$ & $6 / 6$ & $28.5+1.3$ & $6 / 6$ \\
\hline$(21-30)$ & & & & \\
\hline
\end{tabular}

\subsection{EXPERIMENTAL DESIGN}

A 4 (Equivalent levels of noise) $\times 4$ (Illumination levels) x 4 (Text-background colour combinations) full factorial design was used. The experiment was designed to investigate the reading performance in terms of reading time (seconds) for web-based pseudo-text as dependent variable. The experiment was performed in a random order for every subject.

\subsection{DEPENDENT VARIABLE (READING TIME)}

The reading time was used as performance measure in line with the other studies found in the literature $[6,17]$. For the present experimentation, the software code is developed to automatically record the time required (in milliseconds) to perform the task. The clock started recording the time as soon as the subject started reading the text and stopped when the task was completed.

\subsection{INDEPENDENT VARIABLES}

\subsubsection{Illumination level}

A survey was carried out before the experiment to determine the levels of illumination existing in various working 
environments. It is found that the level of illumination existing in these places lies between inadequate to moderate limits. In the light metal fabricating industries the illumination is between $125-220 \mathrm{~lx}$ and in modern machining units is $150-325 \mathrm{~lx}$. Based on the survey four levels of ambient illumination namely 150, 275, 400 and 525 $\mathrm{l} x$ were selected for carrying out the experimental investigations.

\subsubsection{Noise level}

A survey before the experiment is carried out to determine the levels of noise existing in various working environments. The finding of the survey shows that equivalent noise level up to $86 \mathrm{dBA}$ is present in various work places. The minimum level of equivalent noise is found to be around $60 \mathrm{dBA}$. On the basis of these survey four equivalent noise levels namely 60, 70, 80, and $90 \mathrm{dBA}$ were selected for the present research.

\subsubsection{Colour combination}

The global standard for internet audience measurement and analysis shows that the most widely used internet sites are www.yahoo.com, www.microsoft.com, www.msn.com, www.aol.com and www.google.com. These internet sites when analysed show that they use different textbackground colour combinations such as black-text with grey-background, blue-text with white-background, white-text with bluebackground, black/blue/green text with whitebackground. On the basis of this observation four different text colours namely black, blue green white background and black text-grey background are selected. The web pages are generated accordingly for carrying out the experimental investigations. Table 2 shows independent variables selected.

\subsection{EXPERIMENTAL SETUP}

The experimental setup comprises the following subsystems as shown in Figure 1.

1. Pentium-D Computer - 2 Nos. along with TFT-LCD $17^{\prime \prime}$ monitors

2. Web Camera - 1 No. (HCL, 800 by 600 pixels)

3. Noise level meter (Model 33, Make Pulsar, U.K)

4. Digital lux meter (Model 101, range 1 to $50,0001 \mathrm{x}$ )

5. Humiprint system (Type HUMITHERM, 84T, LCD)

6. Audio tape recorder (AIWA make)

7. Light source

\subsection{CONDITION OF WORK PLACE}

The different levels of illumination are achieved using fluorescent lamps while the various levels of equivalent noise are obtained by playing the recorded noise. The recorded noise is a mixture of irrelevant speech, traffic noise, machine noise, etc. Two speakers used for generating equivalent noise levels of required intensity are kept at a distance of 1.5 meters. The levels of noise are measured with the help of noise level meter.

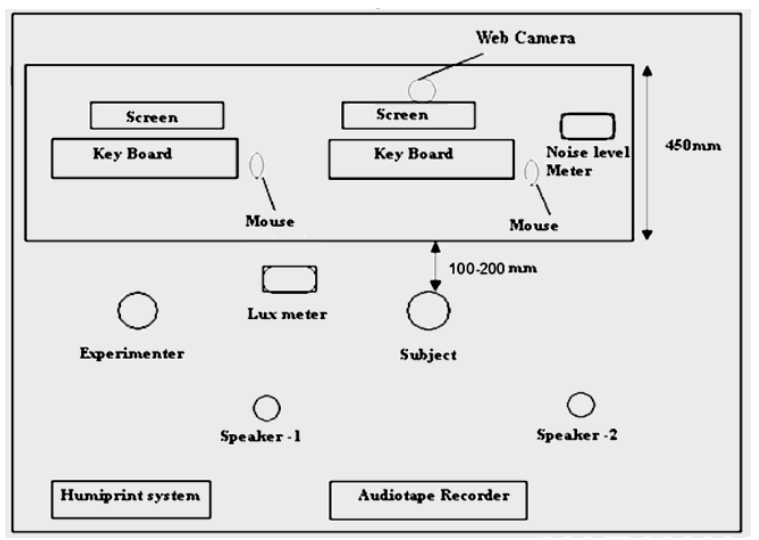

Fig.1. Schematic diagram of the experimental set-up

\subsection{TASK}

The subjects are asked to adopt a normal sitting position and start reading the text line 
by line by moving cursor from their left to right. To ensure that the subjects had read the full text, they are asked to click the mouse when they encountered a particular character while reading. In line with the study of [21], pseudo-text was selected to eliminate any bias which may occur while reading a normal text viz. difficulty level and coherence of the text, skipping of the familiar words, reading speed etc. The pseudo-text (Figure 2) designed contains various string sizes and resembling the text. The number of clicks made by the subjects for a particular character is compared with the total number of the same character present in the text. If the variation is observed to be within $\pm 2 \%$ the readings are accepted otherwise the values are discarded. The subjects however are not told whether the reading time values obtained have been accepted or rejected. After completing reading of the text, the subject clicked the stop button to signal the end of the task. Each subject performed 64 sets of observations. The subjects are provided a rest period of 45 minutes in between each set of experiment.

TABLE 2: INDEPENDENT VARIABLES SELECTED

\begin{tabular}{|c|c|c|c|}
\hline Groups & $\begin{array}{c}\text { Factor A } \\
\text { Illumination } \\
\text { levels }\end{array}$ & $\begin{array}{c}\text { Factor B } \\
\text { Equivalent } \\
\text { noise levels }\end{array}$ & $\begin{array}{c}\text { Factor C Text } \\
\text { background } \\
\text { colour } \\
\text { combination }\end{array}$ \\
\hline $\begin{array}{c}\text { Experiment } \\
\text { (internet use } \\
\text { duration of < } \\
\text { and }>2 \\
\text { hrs/day) }\end{array}$ & $\begin{array}{l}\text { Level-1 }(150 \mathrm{~lx}) \\
\text { Level-2 }(275 \mathrm{~lx}) \\
\text { Level-3 }(400 \mathrm{~lx}) \\
\text { Level-4 }(525 \mathrm{~lx})\end{array}$ & $\begin{array}{l}\text { Level-1 (60 } \\
\text { dBA) Level-2 } \\
\text { (70 dBA) } \\
\text { Level-3 (80 } \\
\text { dBA) Level-4 } \\
\text { (90 dBA) }\end{array}$ & $\begin{array}{l}\text { Level-1 (Black } \\
\text { text-white } \\
\text { background) } \\
\text { Level-2 (Blue } \\
\text { text-white } \\
\text { background) } \\
\text { Level-3 (Green } \\
\text { text- white } \\
\text { background) } \\
\text { Level-4 (Black } \\
\text { text- grey } \\
\text { background) }\end{array}$ \\
\hline
\end{tabular}

\subsection{GENERAL EXPERIMENTAL PROCEDURE}

There were 10 subjects in each group of users (Group 1: subjects with $<2 \mathrm{hrs}$ of internet use/day and Group 2: subjects with $>2$ hrs of internet use/day). The following preparatory steps were undertaken before performing the experiment.

- Each subject selected is briefed about the objective of the experiment and instructions to be followed while performing the experimental task

- The participants completed an informed consent and demographic questionnaire, viz. age, vision, etc. for assessing their experience on the Internet usage.

- The subject related characteristics like age, vision, internet exposure duration are recorded.

- A training session is organized for subjects in order to get them familiarized with how to perform the task. At least one complete run of the experiment was undertaken for this purpose.

After imparting necessary instructions, following steps are taken for both training as well as experimental sessions.

- Subjects took position in front of the computer screen. A reading text is presented to the subject on the computer screen with command buttons for name, age, start, stop, back colours, fore colours, display records, save record, starting time, finishing time (milliseconds), total character and exit.

- The subject was asked to enter name and age in the space provided for the purpose on the computer screen.

- A start signal was given to the subject.

- The subject pressed the command button to get the clock started. The clock was able to record the time in milliseconds.

- The subject started reading the text line by line and is also required to recognize a certain character (e.g. "A" in the text). The subject pressed that character key on 
the keyboard every time he said and that character appeared. The subject's score of character detection is recorded automatically using the software prepared for the purpose.

- The subject pressed "Stop" button at the end of the task.

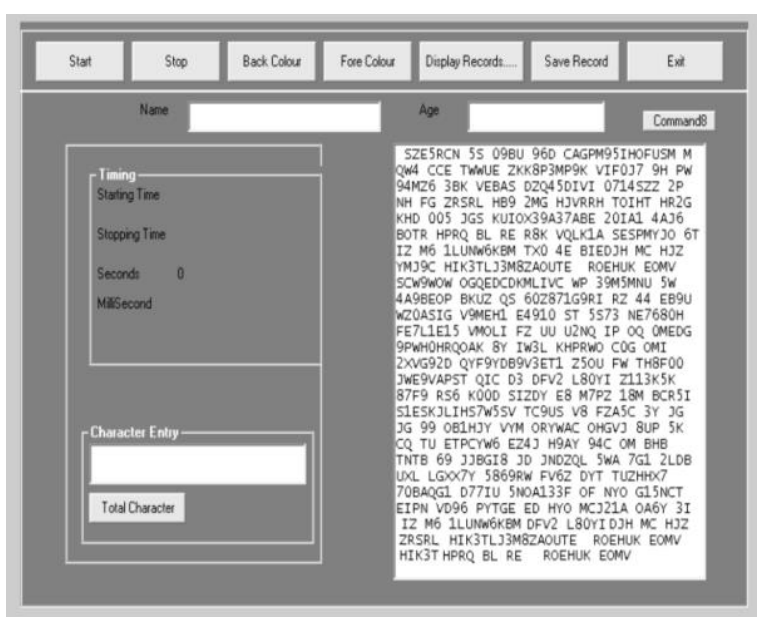

Fig.2. The screen shot of the web page showing command buttons

\section{RESULTS}

The analysis of the data obtained from the experimental studies conducted to determine the task performance of subjects age groups under the influence of equivalent levels of noise, illumination level and text-background colour combinations. The data collected were analysed using SPSS 13.0 for all the studies conducted in the present research. The details of the experimental investigations have been presented as follows:

\subsection{EXPERIMENT-1 FOR GROUP 1 (INTERNET USAGE 2 HOURS AND LESS)}

The profile plots of the interaction effect of level of illumination and equivalent noise level (Figure 3) shows that more reading time is required for all levels of illumination for equivalent noise level-4 $(90 \mathrm{dBA})$ in comparison to other levels of noise except at equivalent noise level-3 (80 $\mathrm{dBA})$ at illumination level-4 (525 lx).
TABLE 3: ANOVA RESULTS

\begin{tabular}{|c|c|c|c|c|}
\hline Source of variation & $\begin{array}{c}\text { Degrees } \\
\text { of } \\
\text { freedom }\end{array}$ & $\begin{array}{l}\text { Mean } \\
\text { Square }\end{array}$ & $\begin{array}{c}\text { F- } \\
\text { value }\end{array}$ & $\begin{array}{c}\mathrm{p}- \\
\text { value }\end{array}$ \\
\hline Illumination level (A) & 3 & 146.875 & 1.039 & 0.391 \\
\hline Equivalent noise level (B) & 3 & $760.237 \mid$ & 13.168 & $<0.001$ \\
\hline $\begin{array}{l}\text { Text-background } \\
\text { combination }(C)\end{array}$ & 3 & 282.512 & 4.065 & 0.017 \\
\hline Subject & 9 & 899.270 & 4.697 & $<0.001$ \\
\hline$A \times B$ & 9 & 111.470 & 3.387 & 0.001 \\
\hline$A \times C$ & 9 & 122.985 & 2.823 & 0.006 \\
\hline $\mathrm{B} \times \mathrm{C}$ & 9 & 109.257 & 2.412 & 0.018 \\
\hline A x subject & 27 & 141.311 & 4.443 & $<0.001$ \\
\hline $\mathrm{B} \times$ subject & 27 & 57.735 & 1.721 & 0.091 \\
\hline C x subject & 27 & 69.499 & 1.573 & 0.105 \\
\hline$A \times B \times C$ & 27 & 101.106 & 2.263 & 0.001 \\
\hline $\mathrm{A} \times \mathrm{B} \times$ subject & 81 & 32.915 & 0.737 & 0.946 \\
\hline A x C x subject & 81 & 43.563 & 0.975 & 0.543 \\
\hline $\mathrm{B} \times \mathrm{C} \times \mathrm{subject}$ & 81 & 45.302 & 1.014 & 0.457 \\
\hline $\mathrm{A} \times \mathrm{B} \times \mathrm{C} \times$ subject & 243 & 44.674 & & \\
\hline
\end{tabular}

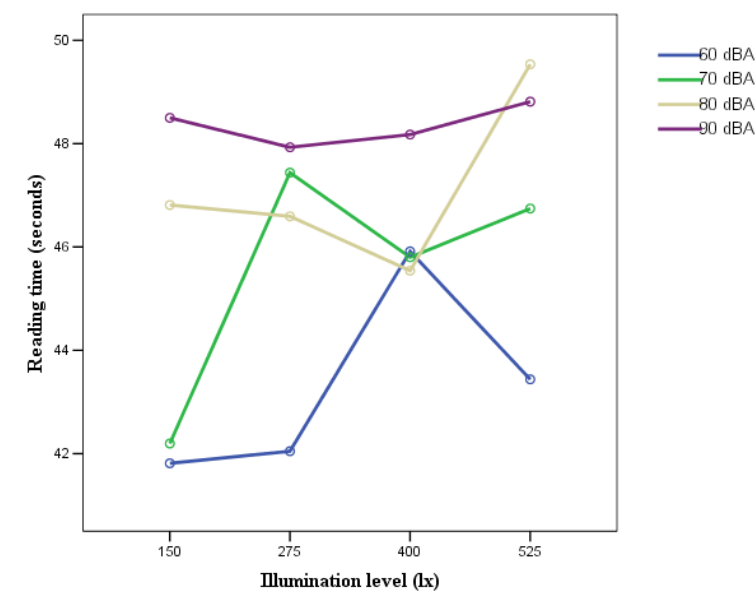

Fig.3. Profile plots between reading time and illumination level for different levels of equivalent noise

The reading time values for equivalent noise level-1 and $-2 \quad(60 \mathrm{dBA}$ and $70 \mathrm{dBA}$ respectively) at illumination level-1 (150 lx) are almost same, while not much difference in the reading time values is seen for equivalent noise level-2, -3 and -4 (70, 80 and $90 \mathrm{dBA}$ respectively) at illumination level-2 (275 lx). The reading time is observed to be nearly same for equivalent noise levels-1, -2 , and -3 (60 dBA, $70 \mathrm{dBA}$ and $80 \mathrm{dBA}$ respectively) at illumination level-3 (400 lx). 


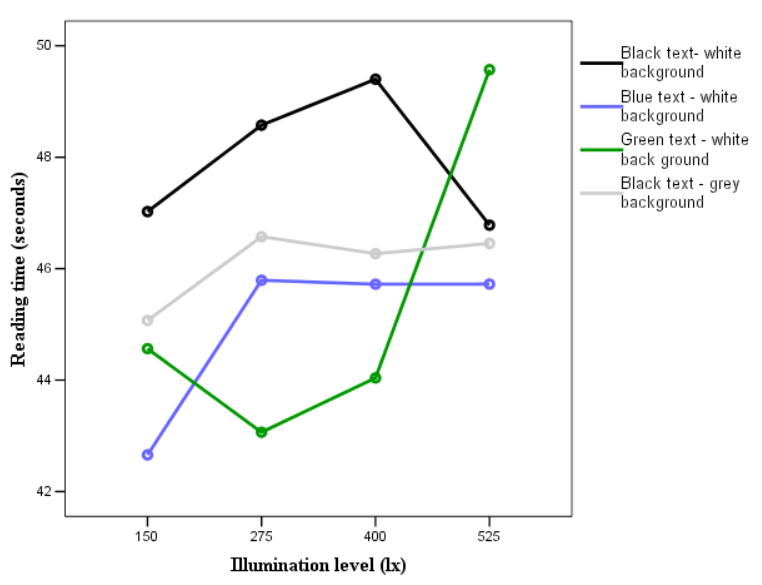

Fig.4. Profile plots between reading time and illumination level for different text-background colour combinations

A large difference in reading time values is reflected for different equivalent noise levels at illumination level-4 (525 lx). The reading performance appeared to be better for equivalent noise level-1 (60 dBA) at all levels of illumination except at illumination level-3 (400 lx). The profile (Figure 4) drawn between reading time and illumination level for different text-background colour combinations shows that reading time values are higher for text-background colour combination-1 (black text-white background) at level of illumination $-4(525 \mathrm{~lx})$ while a lower value is for colour combination-2 (blue text-white background) at illumination level-1 (150 lx). However for text-background colour combination-2 (blue text-white background) and -4 (black text-grey background) not much difference in the reading time values is observed at illumination level-2 (275 lx), -3 $(400 \mathrm{~lx})$ and $-4(525 \mathrm{~lx})$. As far as illumination level $-4(525 \mathrm{~lx})$ is concerned the reading time values for text-background colour combinations-1 (black text-white background), -2 (blue text-white background), and -4 (black text-grey background) are fairly close but the colour combination-3 (green text-white background) requires more time to perform the task.

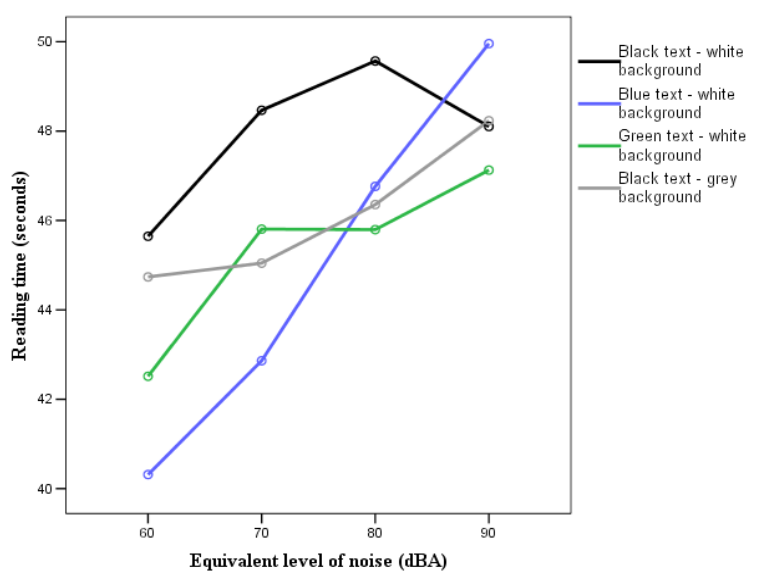

Fig.5. Profile plots between reading time and equivalent noise level for different text-background colour combinations

The minimum time required for completion of the task is about 42 seconds for textbackground colour combination-2 (blue textwhite background) at illumination level-1 $(150 \mathrm{~lx})$ while the text-background colour combination-3 (green text-white background) took maximum time (50 seconds) to complete the reading task at illumination-4 $(525 \mathrm{~lx})$.

The profile plot (Figure 5) between reading time and equivalent noise level shows that as the level of equivalent noise increased, the reading time also increased for all textbackground colour combinations except for text-background colour combination-1 (black text-white background) at equivalent noise level-4 (90 dBA) and text-background colour combination-3 (green text-white background) at equivalent noise level-3 (80 dBA), where reading time values are found to be lower than those at the previous level.

The minimum time required for the reading task is 40 seconds at noise level-1 (60 dBA) for colour combination-2 (blue text-white background). The maximum reading time (50 seconds) is obtained for the equivalent noise- 4 $(90 \mathrm{dBA})$ at text-background colour combination-2 (blue text-white background). 


\subsection{EXPERIMENT-2 FOR GROUP 2 (INTERNET USAGE 2 HOURS AND MORE)}

TABLE 4:ANOVA RESULTS

\begin{tabular}{|c|c|c|c|c|}
\hline Source of variation & $\begin{array}{c}\text { Degree } \\
s \text { of } \\
\text { freedo } \\
m\end{array}$ & $\begin{array}{l}\text { Mea } \\
\text { n } \\
\text { squa } \\
\text { re }\end{array}$ & $\begin{array}{c}\text { F- } \\
\text { valu } \\
\text { e }\end{array}$ & $\begin{array}{c}\mathrm{p}- \\
\text { value }\end{array}$ \\
\hline Illumination level (A) & 3 & $\begin{array}{l}106 . \\
195\end{array}$ & $\begin{array}{c}2.13 \\
3\end{array}$ & $\begin{array}{c}0.11 \\
9\end{array}$ \\
\hline Equivalent noise level (B) & 3 & $\begin{array}{l}226 . \\
843\end{array}$ & $\begin{array}{c}4.69 \\
9\end{array}$ & $\begin{array}{c}0.00 \\
9\end{array}$ \\
\hline $\begin{array}{ll}\text { Text-background } & \text { colour } \\
\text { combination }(C) & \end{array}$ & 3 & $\begin{array}{l}170 . \\
326\end{array}$ & $\begin{array}{c}5.50 \\
2\end{array}$ & $\begin{array}{c}0.00 \\
4\end{array}$ \\
\hline Subject & 9 & $\begin{array}{l}4819 \\
.65\end{array}$ & $\begin{array}{c}73.5 \\
85\end{array}$ & $\begin{array}{c}<0.0 \\
01\end{array}$ \\
\hline$A \times B$ & 9 & $\begin{array}{c}59.8 \\
81\end{array}$ & $\begin{array}{c}1.70 \\
2\end{array}$ & $\begin{array}{c}0.10 \\
2\end{array}$ \\
\hline$A \times C$ & 9 & $\begin{array}{l}122 . \\
810\end{array}$ & $\begin{array}{c}3.37 \\
4\end{array}$ & $\begin{array}{c}0.00 \\
1\end{array}$ \\
\hline $\mathrm{B} \times \mathrm{C}$ & 9 & $\begin{array}{c}68.4 \\
24\end{array}$ & $\begin{array}{c}3.28 \\
2\end{array}$ & $\begin{array}{c}0.00 \\
2\end{array}$ \\
\hline A x subject & 27 & $\begin{array}{c}49.7 \\
92\end{array}$ & $\begin{array}{c}1.16 \\
7\end{array}$ & $\begin{array}{c}0.31 \\
0\end{array}$ \\
\hline B $\mathrm{x}$ subject & 27 & $\begin{array}{c}48.2 \\
77\end{array}$ & $\begin{array}{c}1.78 \\
0\end{array}$ & $\begin{array}{c}0.06 \\
2\end{array}$ \\
\hline $\mathrm{C} \mathrm{x}$ subject & 27 & $\begin{array}{c}30.9 \\
56\end{array}$ & $\begin{array}{c}1.09 \\
2\end{array}$ & $\begin{array}{c}0.40 \\
3\end{array}$ \\
\hline$A \times B \times C$ & 27 & $\begin{array}{c}66.9 \\
17\end{array}$ & $\begin{array}{c}2.31 \\
6\end{array}$ & $\begin{array}{c}<0.0 \\
01\end{array}$ \\
\hline A x B x subject & 81 & $\begin{array}{c}35.1 \\
82\end{array}$ & $\begin{array}{c}1.21 \\
7\end{array}$ & $\begin{array}{c}0.12 \\
9\end{array}$ \\
\hline A x C x subject & 81 & $\begin{array}{c}36.3 \\
99\end{array}$ & $\begin{array}{c}1.26 \\
0\end{array}$ & $\begin{array}{c}0.09 \\
3\end{array}$ \\
\hline $\mathrm{B} \times \mathrm{C} \times$ subject & 81 & $\begin{array}{c}20.8 \\
46\end{array}$ & $\begin{array}{c}0.72 \\
1\end{array}$ & $\begin{array}{c}0.95 \\
7\end{array}$ \\
\hline$A \times B \times C \times$ subject & 243 & $\begin{array}{c}28.8 \\
99\end{array}$ & & \\
\hline
\end{tabular}

The profile plots for level of illumination and equivalent noise level (Figure 6 below) shows that the reading time required to perform the task is minimum for all levels of illumination at equivalent noise level-1 (60 dBA). Reading time values for equivalent noise level-2 (70 $\mathrm{dBA})$ and $-4 \quad(90 \mathrm{dBA})$ were same at illumination level-4 $(525 \mathrm{~lx})$. The reading time values for equivalent noise level-1 (60 $\mathrm{dBA})$ and $-2(70 \mathrm{dBA})$ are quite close to the reading time value at illumination level-3 $(400 \mathrm{~lx})$. Similarly there is not much difference in reading time values for equivalent noise levels-3 (80 dBA) and -4 (90 $\mathrm{dBA})$ at illumination level-3 (400 lx). A large difference in reading time is reflected for equivalent noise levels-1 (60 dBA) and -3 (80 $\mathrm{dBA})$ at illumination level-4 (525 lx). The time required to perform the task is minimum (39.5 seconds) at noise level-1 (60 dBA) and illumination level-1 (150 lx), while the maximum time ( 45.5 seconds) is required to perform the task at noise level-3 (80 dBA) and illumination level-4 (525 lx).

Figure 7 and Figure 8 below show the profile plots for reading time and illumination level for different levels of equivalent noise; and profile plots for reading time and illumination level for different text-background colour combinations, respectively. Explanations are similar.

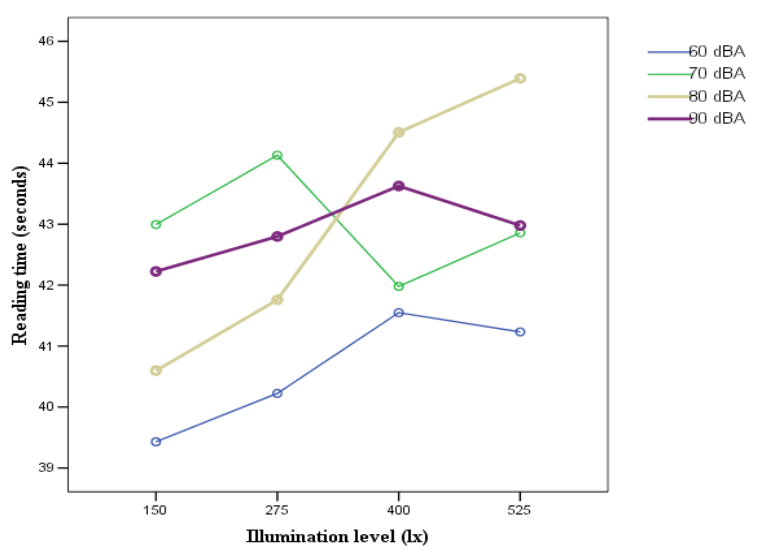

Fig.6. Profile plots between reading time and illumination level for different levels of equivalent noise

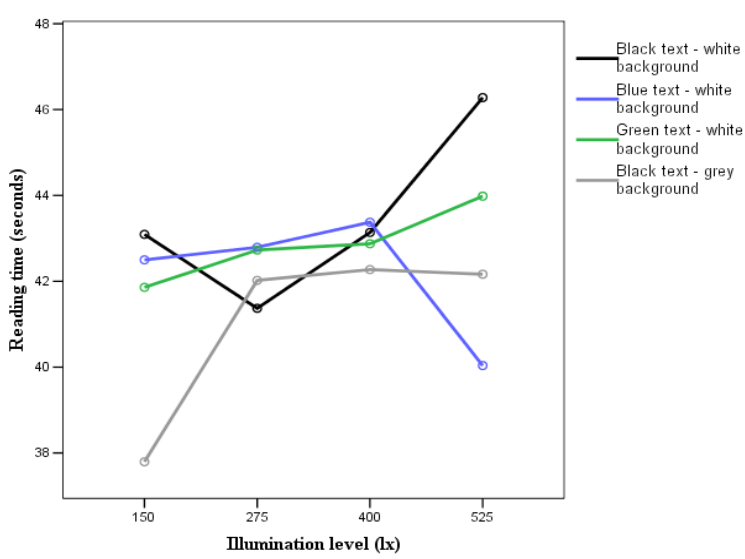

Fig.7. Profile plots between reading time and illumination level for different text-background colour combinations 


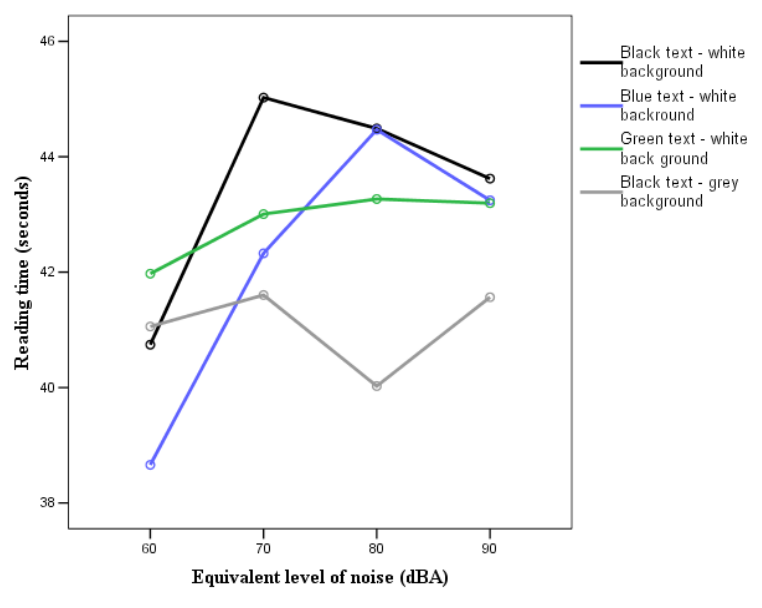

Fig.8. Profile plots between reading time and equivalent noise level for different text-background colour combinations

3.3. COMPARING ANOVA RESULTS FOR EXPERIMENT-1 AND EXPERIMENT-2

Comparing ANOVA results of Table 3 and Table 4 show that level of noise, textbackground colour combination and subject are found to be significant for both groups of subjects when reading time is used as a measure of performance, while illumination level is found to be statistically nonsignificant for both groups. All two-way interactions except equivalent noise with subject and colour combination with subject are significant on reading time for Group 1, while for Group 2 the interactions of illumination level with colour combination and noise level with colour combination are found to be statistically significant. The three-way interaction of illumination level and noise level with text-background colour combination is significant for both groups.

\section{DISCUSSION \& CONCLUSION}

\subsection{LEVEL OF ILLUMINATION}

Level of noise, text-background colour combination and subject were found to be significant subjects when reading time was used as a measure of performance while illumination level.

The study shows that illumination levels are not found significant on reading time for both groups of subjects for the range $150 \mathrm{~lx}$ to 525 $\mathrm{lx}$. These present findings are in line with other studies $[15,13]$. The studies related to web based task has shown no effect of ambient illumination on task performance, also show that there is no effect of ambient illumination on character identification task for different contrast ratios. It was reported that subjects show greater preference for lower illumination $(200 \mathrm{~lx})$ than for higher illumination $(450 \mathrm{~lx})$ but the difference is observed to have no statistical significance However the present findings contradict the findings [10]. The task played a significant role in the selection of level of illumination. Kubo found that the increase in level of illumination resulted in more visual fatigue to the subject [12]. The reason may be that despite having antiglare coating on LCD screen some light still got reflected and amount of glare got enhanced further with the increase of illumination level. In the present paper subjects of age (21-30) did not show significant alteration in reading time when the illumination level varied between $150 \mathrm{~lx}$ to $525 \mathrm{~lx}$. The reason may be that since young individuals have good clarity of optical media of the eye, better focusing power and relatively strong contrast sensitivity, they are better able to adapt to greater variations ambient illumination.

\subsection{LEVEL OF NOISE}

In the present study equivalent noise pressure level is found significant for both groups of subjects. Consequently, with the increase in noise level the reading time is also increasing. Studies conducted in the past on various aspects of noise showed that extreme noise levels are responsible for poor task performance $[13,17]$. However the studies related to the web based task performance under the impact of noise appeared to be almost non-existent. Though some studies 
related to visual display units have been conducted earlier but these cannot be said to be related to the working on internet in a major way. If level of noise is more then 50$60 \mathrm{dBA}$, it is found to be associated with decreased performance in office related task, particularly, mentally demanding tasks [24]. Office noise has been shown to be responsible for performance decrements [25]. Human concentration is found to get hampered due to noise [26]. The reason probably relates to their more sensitive approach towards the working environment as they are not able to come to terms with the level of noise present.

\subsection{Colour Combination}

Results of the present research show that textbackground colour combinations selected in the present study are found significant on reading time for web based task. Blue textwhite background has indicated minimum reading time for noise pressure level of 60 $\mathrm{dBA}$. These results are supported by previous studies by Wang and Chen who found that colour combination is shown to have an effect on reading performance $[27,28]$. The colour difference is found to be a significant factor when search performance and reading performance are evaluated $[27,28]$. In a related study by Huang showed that the search time to find the computer icon got significantly affected by figure / background colour combination [29].

\section{REFERENCES}

[1] Chevalier, A., and Bonnardel, N., Articulation of web site design constraints: effects of the task and designers' expertise. Computers in Human Behavior, 23, pp 2455-2472, 2007.

[2] Barreto, A. B., Jacko, J. A., and Hugh, P., Impact of spatial auditory feedback on the efficiency of iconic human-computer interfaces under conditions of visual impairment. Computers in Human Behavior, 23, pp1211-1231, 2007.
[3] Thomson, W. D., Eye problems and visual display terminals - the facts and the fallacies. Ophthalmic and Physiological Optics, 18 (2), pp 111-119, 1998.

[4] Smith, A.P., Noise and aspects of attention. British Journal of psychology, 82, pp 313-324, 1991.

[5] Carter, E. C., and Carter, R. C., Color and cospicuousness. Journal of the Optical Society of America, 71, pp 723-729, 1981.

[6] Schaik V. P., and Ling, J., Design parameters in Web pages: frame location and differential background contrast in visual search performance. International Journal of Cognitive Ergonomics, 5 (4), 459-471, 2001a.

[7] Schaik, V. P., and Ling, J., The effects of frame layout and differential background contrast on visual search performance in Web pages. Interacting with Computers, 13 (5), 513-525, 2001b.

[8] Shneiderman, B., Designing informationabundant web sites: issues and recommendations. International Journal of Human-Computer Studies, 47, 5, 1997.

[9] Borges, J. A., Morales, I., Rodriguez, N. J., Page Design guidelines developed through usability testing. In: Forsythe, C., Grose, E., Ratner, J. (Eds.), Human Factors and Web Development. Erlbaum, London. 137-152, 1998.

[10] Helander, M. G., and Rupp, B. A., An overview of standards and guidelines for visual display terminals. Applied Ergonomics, 15, pp 185-195, 1984.

[11] Ostberg, O., Accommodation and visual fatigue in display work, In: E. Grandjean and E. Vigliani (Eds.) Ergonomics Aspects of Video Display Terminals, Proceedings of the International Workshop, Taylor \& Francis, London, pp 41-52, 1980.

[12] Kubo, M., Uchi, T., Narutaki, y., Shinomiya, T., Ishii, y.. Development of "Advanced TFT-LCD" with good legibility under any ambient light intensity, Journal of the Society for Information Display 8 (4), pp 299-304, 2000.

[13] Shieh, K. K., and Lin, C. C., Effects of screen type, ambient illumination, and color combination on VDT visual performance and subjective preference. International Journal of Industrial Ergonomics, 26 (5), pp 527-536, 2000. 
[14] Silverstein , L.D.. Human factors for CRT display systems: concepts, methods and research. In: Durrett, H, J. (Ed.), Colour and computer, Acadmic, Orlando, 1887.

[15] Ingraham, B., and Bradburn, E., Converting OLF Materials for Use Online Multi-PALIO: A Case Study. Open Learning Foundation, London, 2003.

[16] Bayumi, A; Shewakh, W and Haleem, A., Design optimal VDU parameters for readability task to alleviate posture discomfort and mental stressors, International Journal of Industrial Engineering \& Technology, vol. 3, no. 2, pp. 53-66, 2013.

[17] Noiwan, J., and Norcio, A. F., Cultural differences on attention and perceived usability: investigating color combinations of animated graphics. International journal of Humancomputer studies, 64, pp 103-122, 2006.

[18] Louis Harris \& Associates, Inc. The Steelcase national study of office environments: Do they work? Grand Rapids, MI: Steelcase Inc 1978.

[19] Chan, T., Yao, M. J., Lai, Y. K., and Shu, S. Y., A study of the comparison of PDA screen and other media on reading performance. Journal of Ergonomic Study, 6 (1), pp 29-38, 2004.

[20] Roufs, J. A. J., and Boschman, M. C., Text quality matrics for visual display units: I. Methodological aspects. Displays, 8, pp 37-43, 1997.

[21] Lin, C. C., and Huang, K. C., Effects of ambient illumination and screen luminance combination on character identification performance of desktop TFT-LCD monitors. International Journal of Industrial Ergonomics, 36, pp 211-218, 2006.

[22] Jones, D. M., Noise. In: Stress and Fatigue in Human Performance, Hockey, G.R.J. (Ed.), Wiley, Chichester, 1983.

[23] Muzammil, M., and Hasan, F., Human performance under the impact of continuous and intermittent noise in a manual machining task. Noise and vibration worldwide, pp 10-15, 2004.

[24] Gavhed D., and Toomingas, A., Observed physical working conditions in a sample of call centres in Sweden and their relations to directives, recommendations and operators' comfort and symptoms. International Journal of Industrial Ergonomics, 37,pp 790-800, 2007.

[25] Veitch, J. A., Office noise and illumination effects on reading- comprehension. Journal of
Environmental Psychology, 10, pp 209-217, 1990.

[26] Banbury, S. P., and Berry, D. C., Office noise and employee concentration: Identifying causes of disruption and potential improvements. Ergonomics, 48 (1), pp 25-37, 2005.

[27] Wang, A. H., and Chen, C. H., Effects of screen type, Chinese typography, and text/background color combination, speed and jump length for VDT leading display on user's reading performance. International Journal of Industrial Ergonomics, 31, pp 249-261, 2003.

[28] Wang, A. H., Chen, C. H., Chen, M. T., Effect of leading display design of dynamic information on user's visual performance and visual fatigue. Journal of the Chinese Institute of Industrial Engineering, 19, pp 69-78, 2002.

[29] Huang, K. C., Effects of computer icons and figure/background area ratios and color combinations on visual search performance on an LCD monitor. Displays, 29 (3), pp 237-242, 2007. 
التأثير المركب للإضاءة والضوضاء وخلفية ولون النص على سهولة تصفح مواقع الإنترنت

\author{
سيد نور الحسن و وليد شويخ \\ قسم الهنسة الصناعيةـ كلية الهندسة_ جامعة جاز ان-المملكة العربيه السعوديه
}

الملخص:

الإنترنت وشبكة المعلومات العالمية واستخدام الحاسب الالى أصبح جز ءا لا يتجزأ من حياة الإنسان. وقد أفادت عدة در اسات بشأن استخدام شاثات العرض المرئي. لتحسين الأداء من مستخدمي الثبكة، أن هناك حاجة للعثّر على مستويات العوامل البيئية وخلفية النص وتركيبة اللون التي قد تخلق الراحة او عدم الراحة للمستخدمين. لذللك، هذه الدراسة تبين آثار الإضاءة الدحيطة و مستوى الضوضاء وتركيية اللون و خلفية النص على الأداء في الفئة العمرية من 20 إلى 31 عاما من فئتين، الأولى ، وفيها بستخدم الاشخاص الحاسب لمدة 2 ساعة / يوم قراءة ، والثانية أكثر من 2 ساعة / يوم. تظهر النتائج أن الوقت المستغرق فى القراءة لايتأثر فى مستوى شدة الاضاءة ما بين 150 و 525 لكلتا الفئتين من المستخدمين. مستوى الضوضاء لة تأثيثر على كلتا الفئتين وكذلك تركيبة الالوان للنص و الخلفية أيضا مؤثر على وقت القراءة. 